\title{
VALIDADE DE UMA ESCALA INTERNACIONAL DE MOTIVAÇÃO DO SERVIÇO PÚBLICO NO CONTEXTO DE SERVIDORES DE INSTITUIÇÕES FEDERAIS DE ENSINO
}

\section{VALIDITY OF AN INTERNATIONAL PUBLIC SERVICE MOTIVATION SCALE IN THE CONTEXT OF SERVERS OF FEDERAL EDUCATION INSTITUTIONS}

\author{
JEFFERSON MENEZES DE OLIVEIRA \\ Administrador na Pró-Reitoria de Gestão de Pessoas - Universidade Federal de Santa Maria (UFSM) \\ Doutorado em Administração pela Universidade Federal de Santa Maria (UFSM) \\ Orcid: http://orcid.org/0000-0003-1937-8751 \\ E-mail: jeffersonmenezes@gmail.com
}

Av. Roraima, 1000. Sala 412 da Reitoria. Bairro Camobi, Santa Maria/RS, CEP: 97.105-900

\section{VANIA DE FÁTIMA BARROS ESTIVALETE}

Professora do PPG em Administração - Universidade Federal de Santa Maria (UFSM)

Doutora em Agronegócios - Universidade Federal do Rio Grande do Sul (UFRGS)

Orcid: http://orcid.org/0000-0002-3277-8613

E-mail: vaniaestivalete@ufsm.br

Submissão: 16/04/2020. Revisão: 29/12/2020. Aceite: 11/01/2021. Publicação: 01/03/2021.

DOI: http://dx.doi.org/10.22277/rgo.v14i2.5386

\section{RESUMO}

O presente estudo teve o objetivo de validar uma escala de mensuração internacional de Motivação do Serviço Público (MSP) no contexto de servidores públicos atuantes em instituições federais de ensino no Brasil. Com abordagem quantitativa, a pesquisa utilizou como estratégia a aplicação de uma survey junto a servidores das carreiras docente e técnico-administrativa. Os resultados do estudo identificaram que o modelo testado apresentou evidências consistentes de validade no contexto pesquisado. A escala de mensuração oferecida, sob o prisma prático, poderá ser replicada por gestores interessados em aprofundar o conhecimento acerca das motivações pró-sociais associadas ao serviço público em suas organizações.

Palavras-chave: Motivação do Serviço Público. Escala de mensuração. Servidores públicos. Instituições Federais de Ensino.

\begin{abstract}
The present study aimed to validate an international measurement scale of Public Service Motivation (PSM) in the context of public servants working in federal educational institutions in Brazil. With a quantitative approach, the research used as a strategy the application of a survey with employees of the teaching and technical-administrative careers. The results of the study identified that the tested model presented consistent evidence of validity in the researched context. The measurement scale offered, from a practical perspective, can be replicated by managers interested in deepening their knowledge about the prosocial motivations associated with public service in their organizations.
\end{abstract}

Keywords: Public Service Motivation. Measurement scale. Public servants. Federal Education Institutions. 
Validade de uma escala internacional de motivação do serviço público no contexto de servidores de instituições federais de ensino

\section{INTRODUÇÃO}

As bases teóricas da Motivação do Serviço Público (MSP) foram concebidas a partir do início dos anos 1990 com o intuito de desenvolver uma teoria de motivação mais abrangente e inclusiva, a qual considera que os mecanismos de desenvolvimento social das instituições influenciam os comportamentos pró-sociais e o autoconceito por parte do indivíduo (PERRY; WISE, 1990; PERRY, 1996; 2000).

Para além das teorias motivacionais clássicas, comumente relacionadas aos processos de escolha racional e incentivos extrínsecos, a MSP é uma força motivacional eminentemente relacionada a objetivos altruístas (MANN, 2006). Ainda que a escolha racional tenha sido considerada entre as bases teóricas da MSP em sua concepção (PERRY; WISE, 1990; PERRY, 1996; 2000), revisões posteriores sinalizaram que o construto está associado a uma instância particular de motivação pró-social relacionada ao serviço público (KIM; VANDENABEELE, 2010; VANDENABEELE; RITZ; NEUMANN, 2018; ABDELMOTALEB; SAHA, 2019). Nesse sentido, a MSP passou a ser concebida como uma força que impulsiona os indivíduos a atuarem pelo bem comum, comprometidos com os valores públicos, com empatia e solidariedade aos demais indivíduos, e sujeitos a sacrifícios pessoais em prol da coletividade (KIM et al., 2013; KIM, 2017).

Ainda que os estudos sobre MSP sejam predominantes em indivíduos de organizações públicas destaca-se que, cada vez mais, o construto é pesquisado em outros contextos. De acordo com Brewer e Selden (1998), a MSP é um traço individual universal que transcende o setor público. Nesse sentido, indivíduos de organizações sem fins lucrativos e do setor privado também podem estar predispostos a prestar um serviço público significativo.

Entre as formas de avaliação para esse fenômeno, destaca-se a extensiva utilização da escala de mensuração de Perry (1996), a qual se assenta nas bases motivacionais racional, normativa e afetiva (KNOKE; WRIGHT-ISAK, 1982). No contexto brasileiro, Buiatti e Shinyashiki (2011) realizaram o processo de validação dessa escala de mensuração, porém, seus resultados indicaram a necessidade de revisar a operacionalização dos itens, bem como a contextualização das dimensões de MSP no país.

Em superação ao modelo de Perry (1996), Kim e Vandenabeele (2010) assinalaram a necessidade de reconstrução do instrumento de mensuração da MSP, a fim de que o mesmo possa ser validado internacionalmente com menos modificações. Esses autores inferem que a MSP é permeada pela noção de autossacrifício e está associada a três tipos aos motivos: instrumental, baseado em valores e de identificação. Nesse sentido, Kim et al. (2013) e Kim (2017) desenvolveram escalas de mensuração que obtiveram propriedades psicométricas satisfatórias em pelo menos 12 países.

Considerando que a compreensão do processo de motivação dos servidores públicos à luz da teoria sobre MSP ainda é incipiente no contexto brasileiro, o presente estudo pretende aprofundar o conhecimento acerca de sua mensuração junto a servidores de instituições que possuem a função sociopolítica de desenvolver e consolidar a cidadania por meio da formação de indivíduos comprometidos com as transformações sociais (MARINHOARAUJO; ALMEIDA, 2016).

Nesse sentido, tendo em vista a escala de mensuração da MSP desenvolvida por Kim (2017) a partir da revisão teórica de Kim e Vandenabeele (2010) e do estudo de Kim et al. (2013), o presente estudo tem o objetivo de validar uma escala de mensuração internacional de MSP no contexto de servidores públicos - docentes e técnico-administrativos - atuantes em instituições federais de ensino no Brasil. 
Considerando que o modelo de mensuração adotado não possui uma versão em português, torna-se necessário realizar um processo prévio de tradução e adaptação de itens. Além disso, justifica-se o presente trabalho pelo esforço em avaliar o comportamento de uma escala internacional de MSP revisada no cenário nacional. Almeja-se que a escala de mensuração apresente evidências de validade e propriedades psicométricas satisfatórias no contexto específico explorado. Sob o prisma prático, o instrumento validado poderá ser utilizado por gestores interessados em aprofundar o conhecimento acerca das motivações pró-sociais associadas ao serviço público em suas organizações.

\section{FUNDAMENTAÇÃO TEÓRICA}

A fundamentação teórica contempla a explanação de bases e conceitos da MSP, bem como os principais modelos de mensuração.

\subsection{BASES E CONCEITOS DE MSP}

As origens do conceito de MSP remontam a um artigo publicado por Rainey (1982), por meio do qual foi investigado o comportamento de gerentes de nível médio de quatro organizações públicas e quatro organizações privadas, a fim de identificar diferenças nas atitudes intrínsecas e extrínsecas dos indivíduos. Os resultados desse estudo mostraram que os gestores públicos foram estatisticamente mais sensíveis a questões relacionadas ao serviço público se comparados aos gestores privados. Portanto, mesmo sem falar explicitamente sobre a MSP, Rainey (1982) apresentou a ideia de que as alavancas motivacionais dos funcionários públicos e privados são diferentes: os primeiros, em particular, são especialmente atraídos por motivações relacionadas ao interesse público.

Posteriormente, uma definição mais consistente para a MSP foi oferecida por Perry e Wise (1990, p. 368), os quais inferiram que esse construto se refere à "predisposição de um indivíduo para responder a motivos baseados, principalmente ou exclusivamente, em instituições e organizações públicas". A partir do estudo de Knoke e Wright-Isak (1982), Perry e Wise (1990) propuseram três bases teóricas ou "motivos" da MSP: racional, normativo e afetivo. Em primeiro lugar, os motivos racionais baseiam-se na maximização da utilidade individual e são manifestados quando os indivíduos querem participar do processo político, estão comprometidos e identificados com um programa público e servem como defensores de um interesse especial ou privado. Em segundo lugar, os motivos normativos baseiam-se no desejo de perseguir o bem comum e, além disso, o interesse público. Em terceiro lugar, os motivos afetivos são fundamentados na emoção humana e são caracterizados por um desejo e disposição para ajudar os outros (PERRY; WISE, 1990; KNOKE; WRIGHT-ISAK, 1982).

O estudo de Rainey (1982) e a definição de Perry e Wise (1990) são referenciados na maioria dos artigos sobre o tema e associam a MSP ao emprego no setor público ou à atuação em instituições públicas, embora o desenvolvimento posterior do conceito tenha se distanciado dessa associação (BOZEMAN; SU, 2015; O'LEARY, 2019). Por tal motivo, torna-se necessário esclarecer o conceito de serviço público e sua interface com os estudos atuais de MSP.

Brewer e Selden (1998) apontam que existem duas premissas não tautológicas ao analisar o serviço público. A primeira premissa consiste em considerá-lo como o ato de fazer algo valioso para a sociedade, conectando motivos altruístas a comportamentos pró-sociais. Nesse sentido, a MSP é um traço universal que pode transcender o setor público. A segunda premissa postula que a MSP é predominante no setor público, ou seja, os indivíduos 
Validade de uma escala internacional de motivação do serviço público no contexto de servidores de instituições federais de ensino

visualizam oportunidades superiores para realizar um serviço público significativo trabalhando em organizações públicas. Sendo assim, ainda que a MSP seja predominante no setor público, indivíduos em muitas organizações sem fins lucrativos e do setor privado também podem estar predispostos a prestar um serviço público significativo. Em alguns casos, esses motivos são muito poderosos e os serviços prestados são vitais para a sociedade (BREWER; SELDEN, 1998).

Nessa visão ampliada, Brewer e Selden (1998) definem a MSP como a motivação para executar serviços públicos, comunitários e sociais significativos. Rainey e Steinbauer (1999) consideram que a MSP remete ao altruísmo inerente ao ato de servir os interesses de uma comunidade de pessoas, um estado, uma nação ou humanidade. Essas definições, portanto, não restringem o conceito ao contexto de indivíduos que trabalham no setor público. Assim, o construto pode também se aplicar a funcionários que desejam servir ao interesse público, trabalhando no setor privado ou sem fins lucrativos (PERRY; HONDEGHEM, 2008).

Além das definições anteriores, que associam o construto a uma forma de motivação pró-social, Vandenabeele (2007) aponta que a MSP transcende o interesse próprio e organizacional. Nesse sentido, compreende crenças, valores e atitudes que motivam os indivíduos a agirem pelo interesse de uma entidade maior (a sociedade), sempre que apropriado.

Kim e Vandenabeele (2010), em refinamento teórico posterior, indicam que a MSP é permeada pela noção de autossacrifício e está associada aos motivos instrumental, baseado em valores e de identificação. Esses autores, portanto, apresentaram uma revisão das bases teóricas apontadas por Perry e Wise (1990), excluindo o interesse privado como componente de MSP.

Os motivos instrumentais são baseados no altruísmo e incluem participar do processo político, de atividades comunitárias e de desenvolvimento social, assim como defender políticas e programas públicos, a fim de realizar um serviço público significativo para a sociedade. Motivos baseados em valores referem-se aos valores públicos finalísticos que os indivíduos desejam alcançar por meio de seus comportamentos e ações. Trata-se de uma internalização de valores, ou seja, os indivíduos podem considerar os valores públicos como sendo seus. São contemplados o interesse público, a responsabilidade social, a democracia, a equidade social, a justiça social, a neutralidade e a responsabilidade. Os motivos de identificação dizem respeito a pessoas ou grupos que os indivíduos desejam servir. Esse processo de identificação, permeado pela empatia, traz a disposição para fazer o bem e até mesmo se sacrificar. Essa base, portanto, enfatiza o comprometimento afetivo de um sujeito ou preocupação com as necessidades de outros indivíduos ou grupos (KIM; VANDENABEELE, 2010).

A partir dessa revisão das bases teóricas, Kim et al. (2013) e Kim (2017) apontam que a MSP se refere a uma força que impulsiona os indivíduos a atuarem pelo bem comum, comprometidos com os valores públicos, com empatia e solidariedade aos demais indivíduos e sujeitos a sacrifícios pessoais em prol da coletividade. Apesar das variações na definição do conceito de MSP, é consensual a presença de um foco em valores e motivos que levam a comportamentos destinados a fazer o bem à sociedade. Enquanto conjunto de crenças e valores que motivam os indivíduos a se envolverem em comportamentos que beneficiam a sociedade (ABDELMOTALEB; SAHA, 2019), a MSP pode ser considerada uma instância particular de motivação pró-social direcionada a beneficiários muitas vezes não identificados (VANDENABEELE; RITZ; NEUMANN, 2018). 


\subsection{DIMENSÕES E ESCALAS DE MENSURAÇÃO DA MSP}

Considerando três tipos de necessidades psicológicas ou motivos (afetivo, normativo e racional), Perry (1996) identificou e operacionalizou uma escala de mensuração da MSP composta por vinte e quatro itens distribuídos em quatro dimensões distintas: i) atração para a elaboração de políticas públicas; (ii) comprometimento com o interesse público/dever cívico; (iii) compaixão; e (iv) autossacrifício. A atração para a elaboração de políticas públicas relaciona-se aos processos de escolha racional, o comprometimento com o interesse público/dever cívico aos processos normativos e a compaixão aos processos afetivos (Perry, 2000). A dimensão auto sacrifício foi complementarmente estabelecida por entender que o ato de servir ao público consiste também em renunciar a recompensas financeiras em prol do bem comum (PERRY, 1996).

A escala validada por Perry (1996) foi extensivamente utilizada em estudos posteriores, sendo analisada em novos contextos e revisada para melhor ajuste e confiabilidade. No Brasil, Buiatti e Shinyashiki (2011) realizaram o processo de validação dessa escala junto a servidores públicos, porém, seus resultados indicaram a necessidade de revisar a operacionalização dos itens, bem como a contextualização das bases teóricas e dimensões da MSP no país.

Em análise ao modelo de Perry (1996), Kim e Vandenabeele (2010) recomendaram a reconstrução do instrumento de mensuração da MSP, a fim de que o mesmo possa ser validado internacionalmente como menor variância configural. Para tanto, esses autores sugeriram como ponto de partida a assunção das bases motivacionais revisadas da MSP (motivo instrumental, baseado em valores e de identificação), assim como a observância da noção de autossacrifício.

A partir dessas constatações, Kim et al. (2013) desenvolveram um modelo de mensuração pelo qual a MSP foi composta por quatro dimensões: Atração para o Serviço Público (ASP), Comprometimento com os Valores Públicos (CVP), Compaixão (COM) e Autossacrifício (AS), cuja composição de itens foi confirmada em 12 países (Austrália, Bélgica, China, Dinamarca, França, Itália, Coreia, Lituânia, Holanda, Suíça, Reino Unido e Estados Unidos). Destaca-se que esses países não diferiram quanto ao número ou à composição das quatro dimensões identificadas, o que conferiu uma invariância configural ao modelo. No entanto, a força da relação entre cada dimensão e seus itens não foi a mesma em todos os países, o que não lhe conferiu invariância métrica.

Posteriormente, Kim (2017) buscou atingir melhores propriedades psicométricas para essa dimensionalidade em pesquisa realizada no contexto coreano. Em decorrência, alguns itens da escala concebida por Kim et al. (2013) foram revisados para melhor adaptação ao contexto institucional do país, aprimorando as propriedades psicométricas do instrumento em diferentes amostras utilizadas na pesquisa. A partir de uma Análise Fatorial Confirmatória (AFC), os resultados do estudo de Kim (2017) suportaram a confiabilidade, a validade convergente e a validade discriminante de um modelo revisado, composto por 29 itens distribuídos nas quatro dimensões da escala internacional (ASP, CVP, COM e AS). Além disso, por considerar que escalas mais curtas são geralmente preferidas para reduzir a carga de trabalho dos entrevistados, Kim (2017) validou também uma versão de 16 itens. O Quadro 1 apresenta as descrições das quatro dimensões revisadas de MSP. 
Validade de uma escala internacional de motivação do serviço público no contexto de servidores de instituições federais de ensino

Quadro 1 - Dimensões revisadas de MSP

\begin{tabular}{|c|l|}
\hline Dimensão & Descrição \\
\hline $\begin{array}{c}\text { Atração para o Serviço } \\
\text { Público (ASP) }\end{array}$ & $\begin{array}{l}\text { Dimensão que analisa a disposição de servir ao público de forma } \\
\text { significativa, de trabalhar pelo bem comum e de participar do processo de } \\
\text { desenvolvimento e implementação de políticas públicas. }\end{array}$ \\
\hline $\begin{array}{c}\text { Comprometimento } \\
\text { com os Valores } \\
\text { Públicos } \\
\text { (CVP) }\end{array}$ & $\begin{array}{l}\text { Dimensão que analisa a disposição pessoal para buscar o interesse público } \\
\text { e os valores públicos. Compreende a defesa da igualdade de oportunidades } \\
\text { e da prestação contínua de serviços públicos, postura ética e preocupação } \\
\text { com as gerações futuras. }\end{array}$ \\
\hline $\begin{array}{c}\text { Compaixão } \\
\text { (COM) }\end{array}$ & $\begin{array}{l}\text { Dimensão que analisa a ligação afetiva com outros membros de uma } \\
\text { categoria social ou de um sistema político. Compreende empatia e } \\
\text { solidariedade com os menos favorecidos, justiça e bem-estar dos outros. }\end{array}$ \\
\hline Autossacrifício & $\begin{array}{l}\text { Considerada uma dimensão que dá suporte às demais, envolve a realização } \\
\text { de sacrifícios pessoais em prol da sociedade. Essa dimensão é bastante } \\
\text { semelhante à existente na escala de Perry (1996). }\end{array}$ \\
\hline
\end{tabular}

Fonte: elaborado pelos autores a partir de Kim et al. (2013) e Kim (2017).

Por fim, além das medidas multidimensionais apresentadas, identifica-se a utilização de escalas unidimensionais ou globais para mensurar a MSP em estudos internacionais (WRIGHT; CHRISTENSEN; PANDEY, 2013). Essas escalas ajudam a evitar preocupações quanto ao potencial de diferenças individuais em número, natureza ou mesmo importância relativa das dimensões. Elas podem permitir que os pesquisadores usem apenas alguns itens para avaliar com precisão o nível geral de MSP de um indivíduo.

\section{MÉTODO}

A presente pesquisa utilizou como estratégia o emprego de uma survey (ou pesquisa de levantamento), que em estudos quantitativos de natureza exploratória serve ao propósito de conhecer o tema abordado, identificar os conceitos iniciais sobre ele, determinar quais conceitos devem ser medidos e como devem ser mensurados, buscar descobrir novas possibilidades e dimensões da população de interesse (BABBIE, 2005).

Para a mensuração da MSP, optou-se pelo teste da escala de Kim (2017), a qual possui 29 itens distribuídos em quatro dimensões de análise: Atração para o Serviço Público (ASP), Comprometimento com os Valores Públicos (CVP), Compaixão (COM) e Autossacrifício (AS). Em contato realizado por meio eletrônico, Sangmook Kim, autor da supracitada escala, apreciou o interesse desta pesquisa em aprofundar a temática no contexto brasileiro, sugerindo a observação de seus estudos sobre dimensionalidade, criação de itens e adaptação de escalas de MSP (KIM, 2017; KIM, 2017b).

Uma vez que o modelo de mensuração adotado não possuía uma versão em português, foi necessário realizar o processo prévio de tradução e adaptação de itens no contexto brasileiro. Por esse motivo, foram adotadas as recomendações de Beaton et al. (2000), os quais prescrevem estágios fundamentais para a tradução e adaptação de itens: (i) tradução inicial; (ii) síntese das traduções; (iii) retradução; (iv) comitê de especialistas; (v) préteste e; (vi) avaliação do processo. O Quadro 2 descreve os procedimentos realizados em cada uma dessas etapas. 
Quadro 2 - Processo de tradução e adaptação dos itens da escala

\begin{tabular}{|c|c|}
\hline Etapa & Descrição \\
\hline $\begin{array}{l}\text { (i) tradução } \\
\text { inicial }\end{array}$ & $\begin{array}{l}\text { A Versão Original (VO) do instrumento teve seus } 29 \text { itens traduzidos, do inglês para o } \\
\text { português, por dois tradutores profissionais (T1 e T2) fluentes na língua inglesa e nativos à } \\
\text { língua portuguesa, independentemente um do outro. Salienta-se que os tradutores } \\
\text { realizaram alguns comentários sobre suas versões, destacando frases desafiadoras ou } \\
\text { pontos que pudessem causar incertezas. }\end{array}$ \\
\hline $\begin{array}{l}\text { (ii) síntese das } \\
\text { traduções }\end{array}$ & $\begin{array}{l}\text { A partir de consultas à VO do instrumento, de comparações entre as traduções realizadas } \\
\text { por T1 e T2 e do conhecimento agregado sobre o tema, foi estabelecida uma primeira } \\
\text { versão dos itens do instrumento em português, denominada V1. }\end{array}$ \\
\hline (iii) retradução & $\begin{array}{l}\text { Realizou-se o processo de retradução da V1 ao inglês. Seguindo as sugestões de Beaton et } \\
\text { al. (2000), tal processo foi realizado por tradutor bilíngue (inglês-português) cuja língua } \\
\text { nativa é a de origem do instrumento de coleta de dados (inglês). Esse tradutor (T3) é natural } \\
\text { e residente nos Estados Unidos e possui } 15 \text { anos de experiência no Brasil. }\end{array}$ \\
\hline $\begin{array}{l}\text { (iv) comitê de } \\
\text { especialistas }\end{array}$ & $\begin{array}{l}\text { Teve o objetivo de analisar todas as versões do questionário (VO, V1 e retradução) e } \\
\text { desenvolver aquela que seria a versão pré-final. O papel do comitê foi revisar o conteúdo } \\
\text { dos itens e chegar a um consenso sobre qualquer discrepância. Além dos pesquisadores, } \\
\text { participaram do comitê quatro profissionais concernentes à área. A primeira integrante é } \\
\text { psicóloga, mestre em administração, doutoranda em administração e atua } \\
\text { profissionalmente na área de psicologia das organizações. A segunda integrante é } \\
\text { professora do magistério superior (servidora pública) em uma universidade federal, } \\
\text { doutoranda em administração e possui formação acadêmica em Administração e Letras- } \\
\text { inglês. O terceiro integrante ocupa o cargo de administrador (servidor público), é mestre } \\
\text { em gestão de organizações públicas e atua na unidade de gestão de pessoas de uma } \\
\text { universidade federal há mais de } 30 \text { anos, sendo que ocupou o cargo de pró-reitor de gestão } \\
\text { de pessoas por alguns períodos. A quarta integrante ocupa o cargo de administradora } \\
\text { (servidora pública), é mestre em gestão de organizações públicas e atua na unidade de } \\
\text { gestão de pessoas de uma universidade federal, possuindo contato frequente com } \\
\text { indivíduos da população-alvo desta pesquisa. Os integrantes do comitê, juntamente com } \\
\text { os pesquisadores, fizeram análises sobre as equivalências semântica, idiomática, } \\
\text { experiencial e conceitual dos itens, chegando à versão pré-final da pesquisa, denominada } \\
\text { V2 }\end{array}$ \\
\hline (v) pré-teste & $\begin{array}{l}\text { O instrumento em sua versão pré-final (V2) foi estruturado em meio online (Google Forms) } \\
\text { e encaminhado a servidores, docentes e técnico-administrativos, de quatro instituições } \\
\text { federais de ensino localizadas no estado do Rio Grande do Sul (duas Universidades e dois } \\
\text { Institutos Federais). O total de respondentes foi de } 38 \text { servidores, sendo } 25 \text { da carreira } \\
\text { técnico-administrativa e } 13 \text { da docente. A idade variou entre } 26 \text { e } 65 \text { anos (média de } 38 \\
\text { anos) e o tempo médio de trabalho na instituição atual foi de } 8 \text { anos. Foi orientado ao } \\
\text { respondente que se posicionasse na escala utilizada (de discordo totalmente a concordo } \\
\text { totalmente) caso compreendesse o significado do item. Adicionalmente, foi oferecida a } \\
\text { possibilidade de responder "não entendi" diante das afirmativas, situação que poderia ser } \\
\text { esclarecida em caixas de texto disponíveis no questionário. Destaca-se que houve uma } \\
\text { compreensão superior a } 90 \% \text { para todos os } 29 \text { itens do instrumento. Os comentários dos } \\
\text { respondentes serviram de base para a realização de alguns ajustes no questionário. }\end{array}$ \\
\hline $\begin{array}{l}\text { (vi) avaliação } \\
\text { do processo }\end{array}$ & $\begin{array}{l}\text { Considerando as etapas anteriores, foi elaborada a versão final do instrumento de coleta } \\
\text { de dados, denominada VF, a qual está disponível na seção de resultados deste estudo. }\end{array}$ \\
\hline
\end{tabular}
Fonte: elaborado pelos autores a partir de Beaton et al. (2000).

As possibilidades de resposta ao instrumento de coleta de dados foram adaptadas para uma escala do tipo Likert de 5 pontos ( 1 = discordância total e $5=$ concordância total), pois, conforme sinalizam Dalmoro e Vieira (2013), essa composição melhor se ajusta a respondentes com diferentes níveis de habilidade no Brasil.

Quanto à população-alvo, foram considerados os servidores públicos ocupantes de cargos efetivos das carreiras docente e técnico-administrativa das instituições federais de ensino. Conforme dados do Portal da Transparência (BRASIL, 2018), esse universo compreende um total de 264.253 servidores públicos federais, sendo 126.260 docentes e

RGO - Revista Gestão Organizacional, Chapecó, v. 14, n. 2, p. 164-184, maio/ago. 2021. 
Validade de uma escala internacional de motivação do serviço público no contexto de servidores de instituições federais de ensino

137.993 técnico-administrativos. Dada a amplitude da população, foi adotada uma amostragem não probabilística por conveniência. Previamente a sua aplicação, ressalta-se que a pesquisa foi analisada e aprovada pelo Comitê de Ética em Pesquisa da instituição promotora.

Uma vez operacionalizado na plataforma Google Forms, o instrumento de coleta de dados foi disponibilizado por meio online. Com o intuito de alcançar potenciais pesquisados em todo o território nacional, foram encaminhados e-mails às reitorias das instituições federais de ensino a fim de sensibilizá-las quanto à disponibilização da pesquisa em seus canais de comunicação. Além disso, foram contatadas entidades representativas das carreiras abordadas, de forma a estimular o repasse da pesquisa aos seus filiados. Em complemento, por meio de consultas aos sites institucionais (informações públicas), foram coletados e-mails de servidores, bem como de subunidades das instituições. O convite para participação na pesquisa, além de disponibilizar o questionário, sugeria seu compartilhamento entre colegas e unidades de trabalho. Esses procedimentos culminaram no retorno de 815 questionários válidos.

Uma vez coletados os dados, foi conduzido o processo de validação do modelo de mensuração relativo à MSP no contexto pesquisado. Para tanto, foi realizada a Análise Fatorial Confirmatória (AFC) pelo método da máxima verossimilhança, a qual tem o objetivo de verificar o quão bem a especificação de fatores combina com a realidade (ajuste do modelo), mostrando evidência de validade de construto, ou seja, atestando que o conjunto de itens medidos realmente reflete o construto latente teórico que aqueles itens devem medir (HAIR et al., 2009).

Para avaliar o ajuste do modelo de mensuração, o presente estudo considerou indicadores absolutos ( $\chi 2$, $\chi 2$ /d.f., RMSR, SRMR, RMSEA e GFI) e incrementais (CFI, NFI e NNFI), conforme parâmetros dispostos na literatura (HAIR et al., 2009; BASTO; PEREIRA, 2012; MALHOTRA; LOPES; VEIGA, 2014). Relativamente à validade de construto foram observadas as validades convergente e discriminante. Para que a validade convergente ocorra, os itens de um construto específico devem convergir ou compartilhar uma elevada proporção de variância em comum. Nesse sentido, Hair et al. (2009) indicam a observação das cargas fatoriais, da Variância Média Extraída (VME) e da confiabilidade. A validade discriminante, por sua vez, consiste no grau em que um construto/fator é verdadeiramente diferente dos demais (HAIR et al., 2009) e ocorre quando o valor da raiz quadrada da VME de cada construto/fator é maior do que o valor de sua correlação com qualquer outro construto/fator constante no modelo (MALHOTRA, 2011). Quanto à necessidade de modificação do modelo de mensuração (aprimoramento), este estudo considerou a análise das estimativas de caminhos, dos índices de modificação (Modification Indices - M.I.) e dos resíduos padronizados.

Por fim, foram analisados os coeficientes de caminho e de determinação $\left(R^{2}\right)$ para avaliar se as dimensões servem de explicação para o construto. Conforme descrito por Cohen (1988), para a área de ciências sociais e comportamentais, o coeficiente de determinação $\left(R^{2}\right)$ representa a magnitude do efeito da variável independente conforme os intervalos: $2 \%(\geq$ $0,02)=$ efeito pequeno, $13 \%(\geq 0,13)=$ efeito médio e $26 \%(\geq 0,26)=$ efeito grande. Para realização dessas análises, em complemento ao SPSS, foi utilizado o software AMOS.

\section{ANÁLISE E DISCUSSÃO DOS RESULTADOS}

Esta seção contempla a análise descritiva do perfil da amostra, bem como o processo de validação do modelo de mensuração da MSP no contexto pesquisado. 


\subsection{PERFIL DA AMOSTRA}

Considerando a natureza da instituição federal de ensino, $58 \%$ dos respondentes atuam em universidades federais, enquanto $42 \%$ atuam em institutos federais. Em relação à lotação, $28,2 \%$ atuam na região Sudeste, $22,8 \%$ na região Nordeste, $21,8 \%$ na região Sul, $18 \%$ na região Centro-Oeste e $9,1 \%$ na região Norte.

Relativamente à categoria funcional, $67,5 \%$ dos respondentes possuem atribuições de natureza técnico-administrativa, enquanto $32,5 \%$ desempenham a atividade docente. Em relação ao exercício de funções de chefia, $65,9 \%$ dos servidores pesquisados não as exercem, enquanto $34,1 \%$ as exercem.

Quanto ao maior grau completo de instrução formal dos pesquisados, $1,8 \%$ informaram o ensino médio, 10,3\% o ensino superior, 35,1\% a especialização, 33,4\% o mestrado e $19,4 \%$ o doutorado. Sendo assim, quase $88 \%$ dos respondentes possuem pósgraduação, ocorrência compatível com a natureza das organizações às quais pertencem.

Em relação ao sexo, identificou-se que $45,6 \%$ dos servidores respondentes informaram o masculino, $54,1 \%$ o feminino e $0,2 \%$ preferiram não responder. Quanto à idade, variou entre 20 e 67 anos, com uma média de 38,6 anos. Por fim, relativamente ao tempo de trabalho no setor público, variou entre zero e 40 anos completos, sendo a média de 8,4 anos.

\subsection{VALIDADE DA ESCALA DE MENSURAÇÃO DA MSP}

Esta subseção tem por finalidade explorar o processo de validação do construto MSP a partir da tradução e adaptação da escala de Kim (2017).

Com suporte dos softwares SPSS e AMOS 18.0, foram conduzidas análises fatoriais confirmatórias pelo método da máxima verossimilhança. Para a avaliação do ajuste do modelo, optou-se por considerar indicadores absolutos ( $\chi 2$, $\chi 2$ /d.f., RMSR, SRMR, RMSEA, GFI e incrementais (CFI, NFI, NNFI). Para atestar a validade de construto, foram analisadas as validades convergente e discriminante.

Relativamente à validade convergente, foram considerados os indicadores de confiabilidade (Alfa de Cronbach e Confiabilidade Composta), os valores significativos das cargas fatoriais padronizadas das variáveis e o índice de Variância Média Extraída (VME) de cada dimensão. Quanto à validade discriminante, ela foi atestada na medida em que a raiz quadrada da VME de cada dimensão mostrou-se maior do que os valores de suas correlações com as demais dimensões do modelo (HAIR et al., 2009).

A Tabela 1 apresenta os resultados referentes à composição inicial do modelo de MSP no contexto da pesquisa. Estão dispostos os valores de média, desvio padrão e carga fatorial padronizada de cada item. 
Validade de uma escala internacional de motivação do serviço público no contexto de servidores de instituições federais de ensino

Tabela 1 - Composição do modelo inicial de MSP

\begin{tabular}{|c|c|c|c|c|c|}
\hline Dim. & № & Item & Média & Desvio & C. F.* \\
\hline \multirow{8}{*}{ 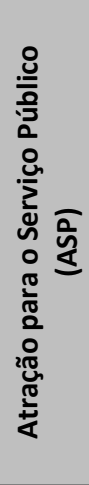 } & M01ASP & Eu gosto de discutir assuntos relacionados a políticas governamentais. & 3,96 & 966, & 607 \\
\hline & M02ASP & $\begin{array}{l}\text { Eu gosto de participar de atividades relacionadas à resolução de } \\
\text { problemas sociais. }\end{array}$ & 3,97 & 916 & ,640 \\
\hline & M03ASP & $\begin{array}{l}\text { Eu tento expressar minhas opiniões pessoais sobre questões } \\
\text { relacionadas a políticas públicas. }\end{array}$ & 3,92 & ,980 & ,555 \\
\hline & M04ASP & Eu quero contribuir para o desenvolvimento da sociedade. & 4,60 & ,579 & ,762 \\
\hline & M05ASP & $\begin{array}{l}\text { Eu quero contribuir para a realização dos princípios constitucionais na } \\
\text { sociedade. }\end{array}$ & 4,46 & 677 & ,783 \\
\hline & M06ASP & $\begin{array}{l}\text { Para mim, é de grande preocupação proteger o sistema de governança } \\
\text { democrática. }\end{array}$ & 4,49 & ,756 & 650 \\
\hline & M07ASP & Servir meu país contribui para minha autorrealização. & 4,15 & 919 &, 519 \\
\hline & M08ASP & Eu quero trabalhar para tornar meu país melhor. & 4,54 & ,669 & ,574 \\
\hline \multirow{8}{*}{ 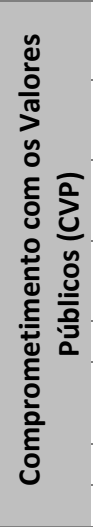 } & M09CVP & $\begin{array}{l}\text { A igualdade de oportunidades para todos os cidadãos deveria ser } \\
\text { garantida. }\end{array}$ & 4,71 & 659 & 698 \\
\hline & M10CVP & $\begin{array}{l}\text { As decisões relativas às políticas públicas deveriam ser democráticas, } \\
\text { mesmo que demandem tempo e esforços. }\end{array}$ & 4,43 & 847 & ,735 \\
\hline & M11CVP & $\begin{array}{l}\text { A dignidade e o bem-estar de todas as pessoas deveriam ser as } \\
\text { preocupações mais importantes em nossa sociedade. }\end{array}$ & 4,59 & 712 & ,702 \\
\hline & M12CVP & $\begin{array}{l}\text { Os interesses das futuras gerações deveriam ser levados em conta ao } \\
\text { se fazer políticas públicas. }\end{array}$ & 4,59 & ,646 & ,549 \\
\hline & M13CVP & Agir eticamente é essencial para os servidores públicos. & 4,92 & 314 & , 280 \\
\hline & M14CVP & $\begin{array}{l}\text { Os servidores públicos devem estar sempre conscientes da } \\
\text { legitimidade de suas atividades. }\end{array}$ & 4,86 & ,397 & ,391 \\
\hline & M15CVP & Eu apoio a proteção dos direitos e liberdades individuais. & 4,69 & ,581 & ,522 \\
\hline & M16CVP & Temos que fazer todos os esforços para exercer a democracia. & 4,65 & ,663 & ,710 \\
\hline \multirow{6}{*}{ 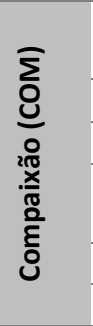 } & M17COM & $\begin{array}{l}\text { É difícil para mim conter meus sentimentos quando vejo pessoas } \\
\text { sofrendo. }\end{array}$ & 4,02 & ,881 & 642 \\
\hline & M18COM & Eu me solidarizo com a condição dos menos privilegiados. & 4,39 & ,704 & 817 \\
\hline & M19COM & Eu tenho empatia com outras pessoas que enfrentam dificuldades. & 4,42 & 714 & ,791 \\
\hline & M20COM & $\begin{array}{l}\text { Eu fico muito chateado (a) quando vejo outras pessoas sendo tratadas } \\
\text { de forma injusta. }\end{array}$ & 4,68 & ,566 & ,662 \\
\hline & M21COM & Considerar o bem-estar dos outros é muito importante. & 4,54 & ,614 & ,749 \\
\hline & M22COM & Eu me importo muito com as outras pessoas. & 4,27 & 723 & ,721 \\
\hline \multirow{7}{*}{ 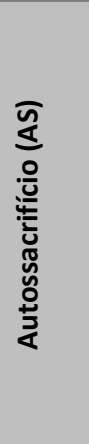 } & M23AS & Estou preparado (a) para fazer sacrifícios pelo bem da sociedade. & 3,63 & 937 & ,780 \\
\hline & M24AS & Eu acredito em colocar o dever cívico antes de si mesmo. & 3,43 & 1,051 & ,669 \\
\hline & M25AS & Estou disposto (a) ao risco de perda pessoal para ajudar a sociedade. & 3,22 & 1,069 & ,786 \\
\hline & M26AS & $\begin{array}{l}\text { Eu acho que as pessoas deveriam devolver à sociedade mais do que } \\
\text { recebem dela. }\end{array}$ & 3,46 & 1,031 & 600 \\
\hline & M27AS & $\begin{array}{l}\text { Eu concordaria com um bom plano para melhorar a vida dos mais } \\
\text { pobres, mesmo que isso me custasse dinheiro. }\end{array}$ & 3,71 & 1,021 & 730 \\
\hline & M28AS & $\begin{array}{l}\text { Servir aos outros me daria uma sensação boa, ainda que isso me } \\
\text { causasse alguma perda. }\end{array}$ & 3,70 & 973 & ,784 \\
\hline & M29AS & $\begin{array}{l}\text { Construir uma sociedade melhor significa mais para mim do que } \\
\text { conquistas pessoais. }\end{array}$ & 3,68 & 949 & 673 \\
\hline
\end{tabular}

*todas as cargas fatoriais padronizadas foram significativas $(p<0,001)$

Fonte: dados da pesquisa (2019).

Observou-se, por meio da Tabela 1, que todas as variáveis apresentaram médias superiores a 3,00 e cargas fatoriais significativas. Por sua vez, a Tabela 2 apresenta os resultados referentes aos indicadores de ajuste do modelo. 
Jefferson Menezes de Oliveira e Vania de Fátima Barros Estivalete

Tabela 2 - Indicadores de ajuste do modelo inicial de MSP

\begin{tabular}{l|c|c}
\hline Indicadores de ajuste & Parâmetros considerados satisfatórios & Modelo inicial de 29 itens \\
\hline$\chi 2$ & $p>0,05 ;$ aceitável $p<0,05$ se $(\chi 2 /$ d.f. $) \leq 5$ & 2570,4 (d.f.=373); $p<0,05$ \\
\hline$\chi 2 /$ d.f. & $\leq 5,00$ & 6,89 \\
\hline SRMR & $\leq 0,080$ & 0,070 \\
\hline RMSR & $\leq 0,050$ & 0,044 \\
\hline RMSEA & $<0,080$ & 0,085 \\
\hline GFI & $\geq 0,900$ & 0,812 \\
\hline CFI & $\geq 0,900$ & 0,805 \\
\hline NFI & $\geq 0,900$ & 0,780 \\
NNFI & $\geq 0,900$ & 0,788 \\
\hline
\end{tabular}

Fonte: dados da pesquisa (2019).

Identificou-se, por meio da Tabela 2, que o modelo inicial apresentou um ajuste insatisfatório em relação aos parâmetros estabelecidos, sinalizando a necessidade de aprimoramento. A Tabela 3, por conseguinte, apresenta as análises referentes à validade de construto (convergente e discriminante) do modelo inicial de MSP.

Tabela 3 - Indicadores de validade de construto do modelo inicial de MSP

\begin{tabular}{llllllll}
\hline & \multicolumn{3}{c}{ Validade convergente } & \multicolumn{3}{c}{ Correlações e validade discriminante } \\
\cline { 2 - 8 } & Alfa & CC & VME & ASP & CVP & COM & AS \\
\hline ASP & 0,831 & 0,85 & 0,41 & $(0,640)$ & & & \\
\hline CVP & 0,806 & 0,80 & 0,35 & $0,516^{* *}$ & $(0,591)$ & & \\
\hline COM & 0,866 & 0,87 & 0,54 & $0,471^{* *}$ & $0,573^{* *}$ & $(0,734)$ & \\
\hline AS & 0,880 & 0,88 & 0,52 & $0,448^{* *}$ & $0,387^{* *}$ & $0,570^{* *}$ & $(0,721)$ \\
\hline
\end{tabular}

Notas: Alfa=Alfa de Cronbach; CC=Confiabilidade Composta; VME=Variância Média Extraída; Valores entre parênteses na diagonal na matriz de correlação apresentam a raiz quadrada da VME (validade discriminante);

**A correlação é significativa no nível 0,01.

Fonte: dados da pesquisa (2019).

Os resultados dispostos na Tabela 3 indicam que a validade discriminante foi lograda para as quatro dimensões (raiz quadrada da VME de cada dimensão é maior do que os valores de suas correlações com as demais dimensões do modelo). Por outro lado, ainda que os índices de confiabilidade tenham sido satisfatórios (Alfas e CCs superiores a 0,7), a validade convergente não foi obtida para todas as dimensões da MSP (ocorrência de cargas fatoriais padronizadas e VMEs com valores inferiores a 0,5 ).

Nesse sentido, buscou-se o aprimoramento do modelo por meio da análise conjunta das cargas fatoriais padronizadas, dos resíduos padronizados e dos índices de modificações (M.I.) oferecidos pelo software AMOS.

Primeiramente, foi realizado o teste de exclusão das variáveis com cargas fatoriais padronizadas (estimativas de caminhos) inferiores a 0,5, conforme recomendado por Hair et al. (2009). Nesse sentido, considerando um procedimento por vez, foram realizadas as exclusões das variáveis "(M13CVP) Agir eticamente é essencial para os servidores públicos" e "(M14CVP) Os servidores públicos devem estar sempre conscientes da legitimidade de suas atividades", com cargas fatoriais padronizadas de 0,280 e 0,391, respectivamente. Ressaltase que esses itens refletem condutas inerentes aos dispositivos legais que regem a atuação dos servidores públicos brasileiros (Brasil, 1988; 1990), ou seja, são consideradas condutas não optativas. Além disso, destaca-se que esses itens obtiveram as maiores médias do modelo (4,92 e 4,86, respectivamente), sinalizando que podem não servir ao propósito de mensurar e distinguir o comprometimento efetivo com os valores públicos o qual, segundo Kim et al. (2013), seria uma predisposição pessoal. 
Validade de uma escala internacional de motivação do serviço público no contexto de servidores de instituições federais de ensino

Na sequência, ao rodar os dados do modelo novamente, identificou-se que a variável "(M15CVP) Eu apoio a proteção dos direitos e liberdades individuais" obteve carga fatorial padronizada inferior a 0,5 $(0,495)$, sendo também realizada sua exclusão do modelo. Essa ocorrência pode ser justificada pela sensibilidade da dimensão CVP ao contexto analisado. De acordo com Kim (2017), a configuração e hierarquia de valores públicos pode diferir entre culturas e países distintos.

Uma vez reespecificado, o modelo passou a contar com 26 variáveis, todas com cargas fatoriais padronizadas superiores a 0,5 . Porém, o ajuste do modelo não fora ainda logrado conforme os parâmetros estabelecidos ( $\chi 2 /$ d.f. $=6,47 ; \quad S R M R=0,066 ; \quad R M S R=0,048$; RMSEA=0,082; $\mathrm{GFI}=0,837 ; \mathrm{CFI}=0,844 ; \mathrm{NFI}=0,821 ; \mathrm{NNFI}=0,828)$. Sendo assim, com intuito de aprimoramento, o modelo passou a ser analisado em função dos resíduos padronizados e das covariâncias entre os erros das variáveis observadas (análise dos índices de modificação M.I.).

Quanto aos resíduos padronizados, eles foram computados para cada variável na matriz de covariância observada no modelo inicial. De acordo com Hair et al. (2009), resíduos padronizados com valor absoluto excedendo $|4,0|$ podem indicar problemas com o item mensurado, motivo pelo qual poderá ser descartado do modelo até que se obtenha validade de construto.

Por sua vez, os M.I. refletem uma aproximação de quanto o qui-quadrado poderia diminuir se fosse incorporada alguma relação (caminho) entre variáveis, não estabelecida a priori. Segundo Hair et al. (2009), o ajuste do modelo pode ser melhorado liberando-se o parâmetro de covariância de erro entre variáveis observadas. Valores de M.I. de aproximadamente 4,00 ou mais sugerem que o ajuste pode ser melhorado significativamente pela liberação do caminho correspondente (HAIR et al., 2009). Porém, a liberação de parâmetros, ou seja, a inclusão de covariâncias entre os erros das variáveis observadas, pode apenas melhorar o ajuste do modelo, em detrimento da validade de construto.

Assim, como esta pesquisa tem por objetivo validar um instrumento internacional de mensuração em um contexto brasileiro específico, os índices de modificação foram considerados prioritariamente para possíveis exclusões de variáveis em detrimento do estabelecimento de covariâncias entre os seus erros, cujas inclusões não contribuem para o alcance da validade de construto. Nesse sentido, foram realizados os seguintes procedimentos e análises até que se obtivesse, simultaneamente, o ajuste do modelo e a validade de construto:

- Primeiramente, foi analisada a dimensionalidade do construto MSP. A partir da análise dos resíduos padronizados, identificou-se que o item "(M06ASP) Para mim, é de grande preocupação proteger o sistema de governança democrática", da dimensão ASP, apresentou resíduos superiores a 4,0 em relação a cinco itens da dimensão CVP (M09CVP, M10CVP, M11CVP, M15CVP e M16CVP). Além disso, considerando os índices de modificação (M.I.), foi analisada a covariância de erro entre construtos (dimensões), a fim de identificar itens que pudessem possuir forte relação com outras dimensões do modelo, que não aquela estabelecida a priori. Nesse sentido, ao analisar os índices de modificação, identificou-se uma expressiva covariância $(M . I .=133,773$ ) entre o item "M06ASP" e a dimensão CVP. Ocorre que a dimensão CVP possui duas variáveis relacionadas ao valor democracia (M10CVP e M16CVP), fato que torna incoerente o conteúdo da variável M06ASP junto à dimensão ASP. A exclusão da variável M06ASP, portanto, resultou na melhoria do ajuste do modelo ( $\chi 2 /$ d.f. $=6,10$; 
Jefferson Menezes de Oliveira e Vania de Fátima Barros Estivalete

SRMR=0,062; RMSR=0,047; RMSEA=0,079; $G F I=0,849 ; \quad C F I=0,858 ; N F I=0,836 ; N N F I=$ $0,843)$;

- Na sequência, com base nos índices de modificação, foram analisadas as covariâncias internas de erro de construto, a fim de identificar itens de uma mesma dimensão que possuem significativas relações, possibilitando a exclusão daquele com menor carga fatorial padronizada. Identificou-se expressiva covariância $(M . I .=212,705)$ entre as variáveis "(M07ASP) Servir meu país contribui para minha autorrealização" e "(M08ASP) Eu quero trabalhar para tornar meu país melhor". Essas sentenças são consideradas comuns no que se refere ao sentimento de atração pelo trabalho voltado ao atendimento do interesse público do país. Além disso, ressalta-se que a variável M07ASP apresentou resíduos padronizados superiores a 4,0 em relação às variáveis M08ASP, M23AS e M24AS. É possível que a sentença "servir meu país" possa ter sido interpretada como uma forma de sacrifício pessoal. Assim, optou-se pela exclusão da variável M07ASP, com menor carga fatorial padronizada em relação à variável M08ASP, resultando na melhoria do ajuste do modelo $(\chi 2 /$ d.f. $=5,25 ; \mathrm{SRMR}=0,056$; RMSR=0,041; RMSEA $=0,072 ; \mathrm{GFI}=0,873 ; \mathrm{CFI}=0,886 ; \mathrm{NFI}=0,863 ; \mathrm{NNFI}=0,873$ );

- Seguindo o processo de análise, identificou-se expressiva covariância (M.I.=131,660) entre as variáveis "(M01ASP) Eu gosto de discutir assuntos relacionados a políticas governamentais" e "(M03ASP) Eu tento expressar minhas opiniões pessoais sobre questões relacionadas a políticas públicas". Observa-se uma grande semelhança de conteúdo entre essas sentenças, motivo pelo qual optou-se pela exclusão da variável M03ASP, com menor carga fatorial padronizada, resultando na melhoria do ajuste do modelo ( $\chi 2 /$ d.f. $=4,92 ; \quad S R M R=0,055 ; \quad R M S R=0,040 ; \quad R M S E A=0,069 ; \quad G F I=0,886$; $\mathrm{CFI}=0,899 ; \mathrm{NFI}=0,877 ; \mathrm{NNFI}=0,887)$;

- A próxima covariância expressiva $(M . I .=100,469)$ foi identificada entre as variáveis "(M27AS) Eu concordaria com um bom plano para melhorar a vida dos mais pobres, mesmo que isso me custasse dinheiro" e "(M28AS) Servir aos outros me daria uma sensação boa, ainda que isso me causasse alguma perda". Ambas as sentenças se referem à disposição de perdas pessoais para colaborar com a coletividade. Sendo assim, optou-se pela exclusão da variável M27AS, com menor carga fatorial padronizada, resultando na melhoria do ajuste do modelo $(\chi 2 /$ d.f. $=4,35 ; \operatorname{SRMR}=0,056$; $\mathrm{RMSR}=0,038$; RMSEA=0,064; $\mathrm{GFI}=0,907 ; \mathrm{CFI}=0,915 ; \mathrm{NFI}=0,893$; NNFI=0,905);

- Na sequência, identificou-se a covariância expressiva (M.I.=82,744) entre as variáveis "(M01ASP) Eu gosto de discutir assuntos relacionados a políticas governamentais" e "(M02ASP) Eu gosto de participar de atividades relacionadas à resolução de problemas sociais". Ambas as sentenças representam a atração pelo serviço público, porém, optou-se pela exclusão da variável M01ASP, com menor carga fatorial padronizada, resultando na obtenção do ajuste do modelo ( $\chi 2 /$ d.f. $=4,06$; $S R M R=0,056 ; R M S R=0,038$; RMSEA=0,061; GFI=0,918; $\mathrm{CFI}=0,927 ; \mathrm{NFI}=0,906 ; \mathrm{NNFI}=0,917)$.

- Uma vez ajustado o modelo, com 21 itens, identificou-se que apenas a dimensão CVP não havia logrado a validade convergente na medida em que o valor de sua VME permanecia inferior a 0,5 $(0,48)$. Buscou-se analisar os cinco itens remanescentes nessa dimensão de forma a verificar a possibilidade de exclusão de alguma variável, tornando admissível a obtenção da validade convergente. Nesse sentido, foi realizada a exclusão da variável "(M12CVP) Os interesses das futuras gerações deveriam ser levados em conta ao se fazer políticas públicas", a qual apresentou a menor carga fatorial padronizada. Dessa forma, foi possível a obtenção da validade convergente 
Validade de uma escala internacional de motivação do serviço público no contexto de servidores de instituições federais de ensino

para a dimensão CVP (VME $=0,52)$. Reitera-se, mais uma vez, a sensibilidade da dimensão ao contexto analisado $(\chi 2 /$ d.f. $=4,28 ; \quad S R M R=0,056 ; \quad R M S R=0,039$; RMSEA=0,063 GFI=0,918; $\mathrm{CFI}=0,927 ; \mathrm{NFI}=0,908 ; \mathrm{NNFI}=0,917)$.

A Tabela 4 apresenta os dados finais do modelo, incluindo médias das dimensões, indicadores de validade convergente, validade discriminante e de ajuste do modelo final com 20 itens. Os indicadores de confiabilidade $(\geq 0,7)$ e $\operatorname{VME}(\geq 0,5)$, bem como as cargas fatoriais padronizadas significativas e superiores a 0,5 sinalizaram a validade convergente. $A$ análise das correlações e valores de raiz quadrada das VMEs, por sua vez, indicaram a validade discriminante.

Tabela 4 - Indicadores do modelo final de MSP

\begin{tabular}{lllllllll}
\hline & Média & \multicolumn{3}{c}{ Validade convergente } & \multicolumn{3}{c}{ Correlações e validade discriminante } \\
\cline { 3 - 8 } & & Alfa & CC & VME & ASP & CVP & COM & AS \\
\hline ASP & 4,40 & 0,758 & 0,80 & 0,50 & $(0,707)$ & & & \\
\hline CVP & 4,59 & 0,808 & 0,81 & 0,52 & $0,433^{* *}$ & $(0,721)$ & & \\
\hline COM & 4,39 & 0,866 & 0,87 & 0,54 & $0,473^{* *}$ & $0,557^{* *}$ & $(0,734)$ & \\
\hline AS & 3,52 & 0,863 & 0,87 & 0,52 & $0,420^{* *}$ & $0,350^{* *}$ & $0,546^{* *}$ & $(0,721)$ \\
\hline
\end{tabular}

Ajuste: $\chi 2 /$ d.f. $=4,28 ;$ SRMR=0,056; RMSR=0,039; RMSEA=0,063 GFI=0,918; CFI=0,927; NFI=0,908; NNFI=0,917

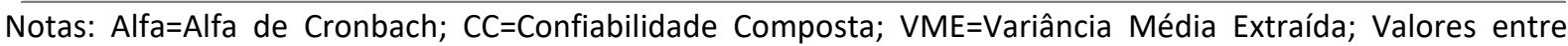
parênteses na diagonal na matriz de correlação apresentam a raiz quadrada da VME (validade discriminante); ${ }^{* *}$ A correlação é significativa no nível 0,01.

Fonte: dados da pesquisa (2019).

Relativamente à incidência do construto no contexto pesquisado, identificou-se que os valores das médias foram superiores a 4,00 para as dimensões ASP, CVP e COM, indicando a prevalência de concordância em relação às afirmativas. Por outro lado, a dimensão AS obteve um valor intermediário de média, entre 3,00 e 4,00, sinalizando que a assunção de perdas pessoais em prol da coletividade possui menor aderência. Esses resultados são compatíveis com os estudos de Kim et al. (2013), no contexto de 12 países, e de Kim (2017), no contexto coreano. Em ambos os casos a dimensão CVP obteve as maiores médias, ao passo que a dimensão AS obteve os menores índices. Igualmente, nesses dois estudos, as dimensões ASP e COM ocuparam posições intermediárias relativamente às médias.

A Figura 1, por sua vez, ilustra graficamente o modelo. Conforme os coeficientes padronizados de caminho e de determinação $\left(R^{2}\right)$, observa-se que a Motivação do Serviço Público - MSP (construto de segunda ordem) está associada às quatro dimensões propostas (construtos de primeira ordem). Destaca-se a maior representatividade da dimensão Compaixão - COM (coeficiente 0,$92 ; R^{2}=0,84$ ), seguida pelas dimensões Comprometimento com os Valores Públicos - CVP (coeficiente 0,72; $R^{2}=0,51$ ), Autossacrifício - AS (coeficiente 0,$65 ; R^{2}=0,43$ ) e Atração para o Serviço Público - ASP (coeficiente 0,$61 ; R^{2}=0,37$ ). Isso indica que as dimensões COM e CVP contribuem mais para o conceito geral de MSP do que as dimensões AS e ASP. 
Figura 1 - Representação gráfica do modelo final de MSP

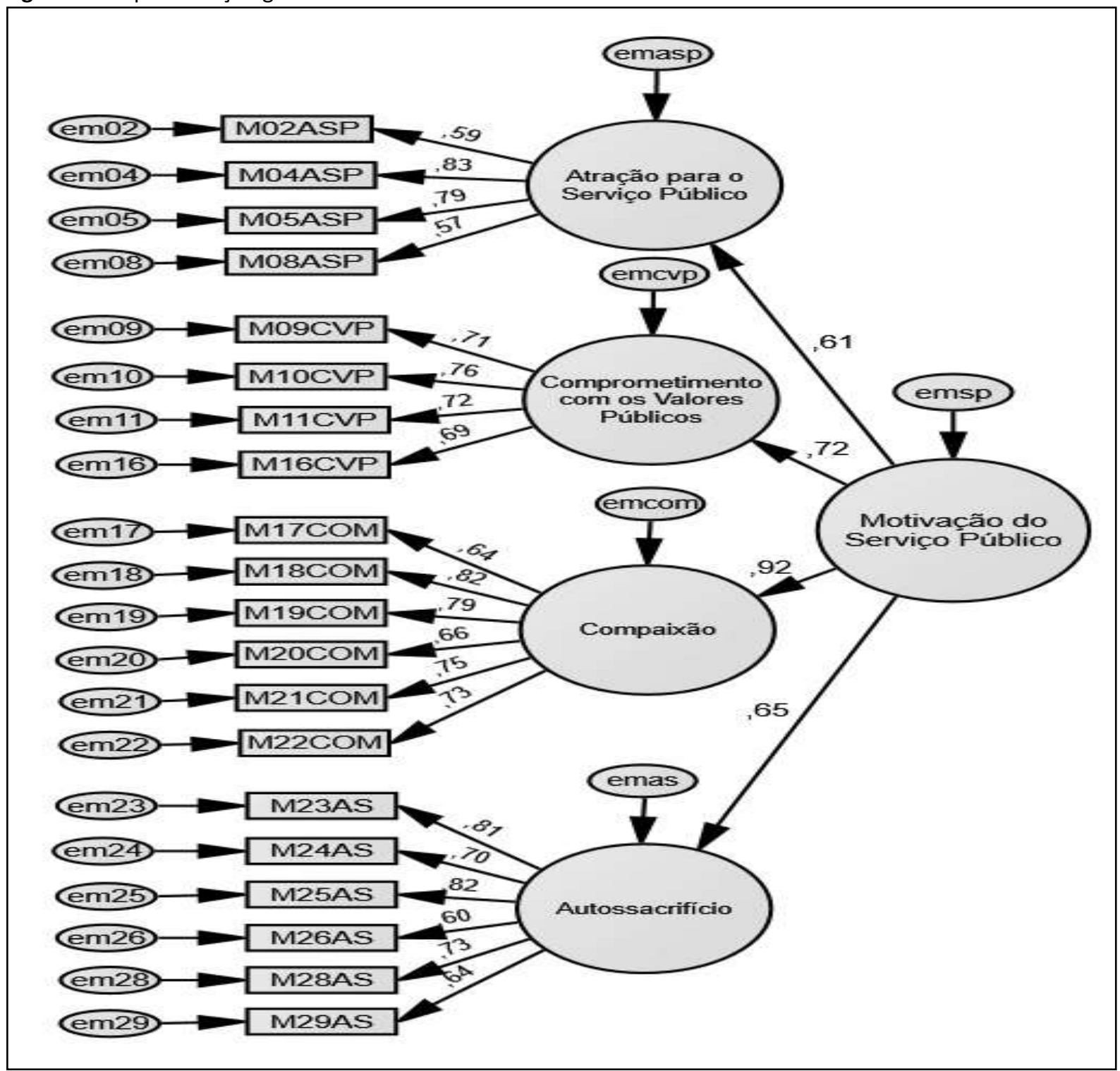

Fonte: elaborada pelos autores (2019).

Percebe-se que a dimensão COM se manteve sem alterações, pois nenhuma variável do modelo inicial foi excluída. Por sua vez, a dimensão AS teve apenas uma variável excluída (M27AS), por ser considerada muito semelhante a outra variável da mesma dimensão (M28AS), procedimento que melhorou o ajuste do modelo. Destaca-se, ainda, que essas dimensões obtiveram os melhores índices de confiabilidade. Tais achados estão consonantes com a literatura internacional, a qual aponta que as dimensões COM e AS são as de maior consenso entre as culturas, obtendo menores discrepâncias nos seus significados, os quais podem ser considerados universais (KIM et al., 2013; KIM, 2017).

Por outro lado, algumas considerações são necessárias diante dos resultados referentes às dimensões ASP e CVP, visto que elas necessitaram de um maior número de exclusões de variáveis até que se obtivesse o ajuste do modelo, assim como a validade de construto.

$\mathrm{Na}$ dimensão ASP, primeiramente, identificou-se a existência de uma variável associada ao conteúdo da dimensão CVP. Trata-se da M06ASP: "Para mim, é de grande preocupação proteger o sistema de governança democrática", a qual foi excluída pela 
Validade de uma escala internacional de motivação do serviço público no contexto de servidores de instituições federais de ensino

sobreposição de significado com as variáveis M10CVP e M16CVP. Os itens remanescentes na dimensão ASP evidenciaram, no contexto brasileiro, a prevalência dos motivos instrumentais relacionados à intenção de realizar um serviço público significativo para a sociedade e o país (KIM; VANDENABEELE, 2010; KIM et al., 2013), em detrimento da intenção de participação no processo de políticas públicas (PERRY; WISE, 1990), cujos itens foram excluídos. Esse resultado pode ser justificado pelo fato de que a formulação de políticas públicas não é inerente às funções técnico-administrativas e aos cargos de docência em Universidades e Institutos Federais no Brasil.

A dimensão CVP, por sua vez, diz respeito à predisposição pessoal de buscar o interesse público e os valores públicos, representando os motivos baseados em valores (KIM; VANDENABEELE, 2010). Sendo assim, relaciona-se a valores públicos aos quais as pessoas desejam contribuir por meio de suas ações (KIM, 2017). De acordo com Kim (2017), a ordem de prioridade entre os valores públicos pode diferir entre os países, sendo que, no contexto explorado, foram mantidos os itens M10CVP e M16CVP, referentes à democracia (PERRY; VANDENABEELE, 2015), e os itens M09CVP e M11CVP, referentes a direitos humanos (KIM; VANDENABEELE, 2010). Considerando que as especificidades das instituições políticas de um país afetam as pessoas em termos dos valores públicos que desejam promover (KIM, 2017), é admissível que essa dimensão se torne mais sensível a culturas e contextos distintos. É possível, portanto, que o contexto analisado apresente ordem ou prioridade de valores públicos diferenciadas de outros contextos.

Em compilação, o Quadro 3 apresenta um guia norteador de análises futuras referentes à aplicação do modelo validado para o contexto brasileiro.

Quadro 3 - Guia norteador de análises da MSP no contexto brasileiro

\begin{tabular}{|c|c|c|}
\hline Dimensão & Descrição & Itens \\
\hline $\begin{array}{l}\text { Atração para o } \\
\text { Serviço Público } \\
\text { (ASP) }\end{array}$ & $\begin{array}{l}\text { Dimensão que, baseada em motivos instrumentais, analisa a intenção de } \\
\text { realizar um serviço público significativo para a sociedade e o país. Mensura a } \\
\text { disposição para participar de atividades relacionadas à resolução de problemas } \\
\text { sociais, assim como o empenho em contribuir para a realização dos princípios } \\
\text { constitucionais na sociedade. Compreende a intenção de atuar para tornar o } \\
\text { país melhor, promovendo o desenvolvimento da sociedade. }\end{array}$ & $\begin{array}{l}\text { M02ASP } \\
\text { M04ASP } \\
\text { M05ASP } \\
\text { M08ASP }\end{array}$ \\
\hline $\begin{array}{l}\text { Comprometimento } \\
\text { com os Valores } \\
\text { Públicos } \\
\text { (CVP) }\end{array}$ & $\begin{array}{l}\text { Dimensão que, a partir de motivos baseados em valores, analisa o julgamento } \\
\text { pessoal em relação aos interesses e valores públicos. Mensura o } \\
\text { comprometimento com os valores públicos relacionados ao exercício da } \\
\text { democracia, à garantia da igualdade de oportunidades e à preocupação com a } \\
\text { dignidade e bem-estar da coletividade. }\end{array}$ & $\begin{array}{l}\text { M09CVP } \\
\text { M10CVP } \\
\text { M11CVP } \\
\text { M16CVP }\end{array}$ \\
\hline $\begin{array}{l}\text { Compaixão } \\
\text { (COM) }\end{array}$ & $\begin{array}{l}\text { Dimensão que, baseada em motivos de identificação, analisa a ligação afetiva } \\
\text { do indivíduo com outros membros de uma categoria social ou de um sistema } \\
\text { político. Mensura a empatia e a solidariedade com os menos favorecidos, a } \\
\text { reação diante de injustiças e a preocupação com as pessoas. }\end{array}$ & $\begin{array}{l}\text { M17COM } \\
\text { M18COM } \\
\text { M19COM } \\
\text { M20COM } \\
\text { M21COM } \\
\text { M22COM }\end{array}$ \\
\hline $\begin{array}{c}\text { Autossacrifício } \\
\text { (AS) }\end{array}$ & $\begin{array}{l}\text { Considerada uma dimensão que dá suporte às demais, analisa a disposição para } \\
\text { a assunção de sacrifícios pessoais em prol da sociedade. Nesse sentido, } \\
\text { mensura a prioridade dada ao bem da sociedade em detrimento de conquistas } \\
\text { ou bens pessoais. }\end{array}$ & $\begin{array}{l}\text { M23AS } \\
\text { M24AS } \\
\text { M25AS } \\
\text { M26AS } \\
\text { M28AS } \\
\text { M29AS }\end{array}$ \\
\hline
\end{tabular}

Fonte: elaborado a partir de Perry e Wise (1990), Perry (1996), Kim e Vandenabeele (2010), Kim et al. (2013), Perry e Vandenabeele (2015), Kim (2017) e dos dados da pesquisa (2019).

Diante do exposto, após as adaptações realizadas, o modelo testado apresentou evidências consistentes de validade no contexto dos servidores públicos atuantes nas instituições federais de ensino. A escala de mensuração disponibilizada, sob o prisma prático, 
poderá ser replicada por gestores interessados em aprofundar o conhecimento acerca das motivações pró-sociais associadas ao serviço público em suas instituições.

\section{CONSIDERAÇÕES FINAIS}

Considerando que a MSP está associada aos motivos instrumental, baseado em valores e de identificação, bem como à noção de autossacrifício (KIM; VANDENABEELE, 2010), este estudo verificou a adequação da composição de dimensões e itens propostos por Kim (2017) no contexto de servidores públicos atuantes em instituições federais de ensino no Brasil.

A partir dos processos de tradução e adaptação, os 29 itens concebidos por Kim (2017) foram testados junto à população-alvo (815 servidores). Em decorrência, por meio da técnica de Análise Fatorial Confirmatória (AFC), as quatro dimensões revisadas de MSP foram confirmadas no contexto brasileiro. Nesse sentido, um modelo de 20 itens obteve ajuste e validade de construto com índices considerados satisfatórios. As dimensões Compaixão (COM) e Autossacrifício (AS) confirmaram seu caráter mais universal, com poucas alterações em relação ao modelo original. Por outro lado, as dimensões Atração para o Serviço Público (ASP) e Comprometimento com os Valores Públicos (CVP) necessitaram de um maior número de exclusões de variáveis até que se obtivesse o ajuste do modelo, assim como a validade de construto.

Os resultados descritivos indicaram que os servidores docentes e técnicoadministrativos, em geral, possuem uma expressiva inclinação pró-social, considerada profícua nos processos de formação de cidadãos, promoção da igualdade social e produção e compartilhamento do conhecimento.

Entre as limitações, por se tratar de uma pesquisa realizada em meio eletrônico, houve dificuldade em localizar e-mails individuais nos sites das instituições, ocorrências de endereços desatualizados e possibilidade de "lixo eletrônico". Esses fatos podem ter limitado o controle da amostra e a taxa de resposta da pesquisa.

No que tange ao contexto analisado, o presente estudo teve por limitação a abordagem exclusiva de trabalhadores efetivos da esfera federal e, restritamente, aqueles lotados em instituições de ensino. Essa delimitação, considerada necessária à operacionalização da pesquisa, abreviou a compreensão do fenômeno a uma instância particular do serviço público brasileiro.

Quanto à escala utilizada para a mensuração do construto, ainda que o anonimato dos pesquisados tenha sido assegurado, indaga-se sobre a existência de resultados "inflados". Existe a possibilidade de "viés de desejabilidade social", ou seja, os indivíduos podem assinalar respostas mais desejáveis do ponto de vista social, em vez de expressar seus verdadeiros sentimentos (KIM; KIM, 2016). Tal limitação pode ter afetado principalmente os resultados das dimensões Compaixão e Autossacrifício, na medida em que mensuram empatia, solidariedade e disposição para a assunção de sacrifícios pessoais em prol da coletividade, condutas socialmente desejáveis e esperadas dos servidores públicos.

Diante do efetivo processo de validação da escala de mensuração no contexto explorado, sugere-se a replicação, de forma a avaliar suas propriedades psicométricas em novas conjunturas, bem como a inclusão de outros construtos possivelmente relacionados à MSP, incluindo a investigação de antecedentes e consequentes para o fenômeno.

Sugere-se o aprofundamento do possível lado "sombrio" da MSP. De acordo com Vandenabeele, Ritz e Neumann (2018), um indivíduo com alto nível de MSP, que não encontra na organização meios para concretizá-la, pode passar por processos de exaustão e frustração. Essa ocorrência pode originar resultados negativos para o indivíduo, para seus colegas e para 
Validade de uma escala internacional de motivação do serviço público no contexto de servidores de instituições federais de ensino

a organização. Pesquisas futuras poderão ser conduzidas no sentido de investigar se as organizações, em especial as públicas, estão sendo capazes de prover os meios adequados para que indivíduos com MSP efetivamente se engajem em comportamentos de serviço público voltados ao bem-estar da sociedade.

Além disso, recomenda-se que a MSP tenha sua perspectiva combinada com a avaliação de incentivos extrínsecos (ANDERSEN, 2009). Dessa forma, torna-se possível comparar os diferentes impactos que motivações altruístas e racionais (voltadas ao interesse próprio) possuem sobre o comportamento e o desempenho dos indivíduos (CAVALCANTE et al., 2015).

Quanto às técnicas de pesquisa, recomenda-se a realização de estudos longitudinais, bem como a adoção de abordagens experimentais, para melhor compreender as relações causais entre a MSP e seus resultados, sobretudo, ao longo do tempo. Além disso, propõe-se a adoção de métodos qualitativos, tais como entrevistas e observações, para ampliar a compreensão de como as organizações dos três setores da sociedade (Estado, Mercado e Sociedade Civil) podem influenciar a MSP, e de que forma processos psicológicos e comportamentais estão associados.

\section{REFERÊNCIAS}

ABDELMOTALEB, M.; SAHA, S. K. Corporate Social Responsibility, Public Service Motivation and Organizational Citizenship Behavior in the Public Sector. International Journal of Public Administration, v. 42, n. 11, p. 929-939, 2019. DOI: https://doi.org/10.1080/01900692.2018.1523189.

ANDERSEN, L. B. What determines the behaviour and performance of health professionals? Public service motivation, professional norms and/or economic incentives. International Review of Administrative Sciences, v. 75, n. 1, p. 79-97, 2009. DOI: https://doi.org/10.1177/0020852308099507.

BABBIE, E. Métodos de pesquisas de survey. Belo Horizonte: Editora UFMG, 2005.

BASTO, M.; PEREIRA, J. M. An SPSS R-menu for ordinal factor analysis. Journal of statistical software, v. 46, n. 4, p. 1-29, 2012. DOI: http://dx.doi.org/10.18637/jss.v046.i04.

BEATON, D. E.; BOMBARDIER, C.; GUILLEMIN, F.; FERRAZ, M. B. Guidelines for the process of cross-cultural adaptation of self-report measures. Spine, v. 25, n. 24, p. 3186-3191, 2000. DOI: https://doi.org/10.1097/00007632-200012150-00014.

BRASIL. Constituição da República Federativa do Brasil de 1988. Disponível em: http://www.planalto.gov.br. Acesso em: 30 maio 2018.

BRASIL. Lei no 8.112, de 11 de dezembro de 1990. Dispõe sobre o regime jurídico dos servidores públicos civis da União, das autarquias e das fundações públicas federais. Disponível em: http://www.planalto.gov.br. Acesso em: 13 jun. 2018.

BRASIL. Portal da Transparência: Servidores (Dados de abril/2018). Disponível em: http://www.portaltransparencia.gov.br/servidores/. Acesso em: 11 jun. 2018. 
BREWER, G. A.; SELDEN, S. C. Whistle blowers in the federal civil service: New evidence of the public service ethic. Journal of public administration research and theory, v. 8, n. 3, p. 413-440, 1998. DOI: https://doi.org/10.1093/oxfordjournals.jpart.a024390.

BOZEMAN, B.; SU, X. Public service motivation concepts and theory: A critique. Public Administration Review, v. 75, n. 5, p. 700-710, 2015. DOI: https://doi.org/10.1111/puar.12248.

BUIATTI, C. L.; SHINYASHIKI, G. T. Gestão de RH no setor público: validação da escala de PSM-Public Service Motivation. Iberoamerican Journal of Industrial Engineering, v. 3, n. 5, p. 118-139, 2011. DOI: https://www.doi.org/10.13084/2175-8018.v03n05a08.

CAVALCANTE, C. E.; SOUZA, W. J. D.; MOL, A. L. R.; PAIVA, J. A. Motivação para entrada de voluntários em ONG brasileira. Revista de Administração, São Paulo, v. 50, n. 4, p. 523-540, 2015. DOI: http://dx.doi.org/10.5700/rausp1217.

COHEN, J. Statistical power analysis for the behavioral sciences. 2. ed. New York: Psychology Press, 1988.

DALMORO, M.; VIEIRA, K. M. Dilemas na construção de escalas Tipo Likert: o número de itens e a disposição influenciam nos resultados? Revista gestão organizacional, v. 6, n. 3, 2013. DOI: https://doi.org/10.22277/rgo.v6i3.1386.

HAIR, J. F.; BLACK, W. C.; BABIN, B. J.; ANDERSON, R. E.; TATHAM, R. L. Análise multivariada de dados. 6. ed. Porto Alegre: Bookman, 2009.

KIM, S.; VANDENABEELE, W. A strategy for building public service motivation research internationally. Public administration review, v. 70, n. 5, p. 701-709, 2010. DOI: https://doi.org/10.1111/j.1540-6210.2010.02198.x.

KIM, S.; VANDENABEELE, W.; WRIGHT, B. E.; ANDERSEN, L. B.; CERASE, F. P.; CHRISTENSEN, R. K.; DESMARAIS, C.; KOUMENTA, M.; LEISINK, P.; LIU, B.; PALIDAUSKAITE, J.; PEDERSEN, L. H.; PERRY, J. L.; RITZ, A.; TAYLOR, J.; VIVO, P. D. Investigating the structure and meaning of public service motivation across populations: Developing an international instrument and addressing issues of measurement invariance. Journal of Public Administration Research and Theory, v. 23, n. 1, p. 79-102, 2013. DOI: https://doi.org/10.1093/jopart/mus027.

KIM, S. H.; KIM, S. Social desirability bias in measuring public service motivation. International Public Management Journal, v. 19, n. 3, p. 293-319, 2016. DOI: https://doi.org/10.1080/10967494.2015.1021497.

$\mathrm{KIM}, \mathrm{S}$. Developing an item pool and testing measurement invariance for measuring public service motivation in Korea. International Review of Public Administration, p. 1-14, 2017. DOI: https://doi.org/10.1080/12294659.2017.1327113. 
Validade de uma escala internacional de motivação do serviço público no contexto de servidores de instituições federais de ensino

KIM, S. (b). Comparison of a Multidimensional to a Unidimensional Measure of Public Service Motivation: Predicting Work Attitudes. International Journal of Public Administration, v. 40, n. 6, p. 504-515, 2017. DOI: https://doi.org/10.1080/01900692.2016.1141426.

KNOKE, D.; WRIGHT-ISAK, C. Individual motives and organizational incentive systems. Research in the Sociology of Organizations, v. 1, n. 2, p. 209-254, 1982.

MALHOTRA, N. K. Pesquisa de marketing: uma orientação aplicada. 6.ed. Porto Alegre: Bookman, 2011.

MALHOTRA, N. K.; LOPES, E. L.; VEIGA, R. T. Modelagem de equações estruturais com Lisrel: uma visão inicial. REMark, v. 13, n. 2, p. 27, 2014. DOI:

https://doi.org/10.5585/remark.v13i2.2698.

MARINHO-ARAUJO, C. M.; ALMEIDA, L. S. Abordagem de competências, desenvolvimento humano e educação superior. Psicologia: Teoria e Pesquisa, v. 32, n. SPE, 2016. DOI: https://doi.org/10.1590/0102-3772e32ne212.

MANN, G. A. A motive to serve: Public service motivation in human resource management and the role of PSM in the nonprofit sector. Personnel Administration, v. 35, n. 1, p. 33-48, 2006. DOI: https://doi.org/10.1177/009102600603500103.

O'LEARY, C. Public service motivation: A rationalist critique. Public Personnel Management, v. 48, n. 1, p. 82-96, 2019. DOI: https://doi.org/10.1177/0091026018791962.

PERRY, J. L.; WISE, L. R. The motivational bases of public service. Public administration review, p. 367-373, 1990. DOI: https://doi.org/10.2307/976618.

PERRY, J. L. Measuring public service motivation: An assessment of construct reliability and validity. Journal of public administration research and theory, v. 6, n. 1, p. 5-22, 1996. DOI: https://doi.org/10.1093/oxfordjournals.jpart.a024303.

PERRY, J. L. Bringing society in: Toward a theory of public-service motivation. Journal of public administration research and theory, v. 10, n. 2, p. 471-488, 2000. DOI: https://doi.org/10.1093/oxfordjournals.jpart.a024277.

PERRY, J. L.; HONDEGHEM, A. Building theory and empirical evidence about public service motivation. International public management journal, v. 11, n. 1, p. 3-12, 2008. DOI: https://doi.org/10.1080/10967490801887673.

PERRY, J. L.; VANDENABEELE, W. Public service motivation research: Achievements, challenges, and future directions. Public Administration Review, v. 75, n. 5, p. 692-699, 2015. DOI: https://doi.org/10.1111/puar.12430.

RAINEY, H. G. Reward preferences among public and private managers: In search of the service ethic. The American Review of Public Administration, v. 16, n. 4, p. 288-302, 1982. DOI: https://doi.org/10.1177/027507408201600402. 
RAINEY, H. G.; STEINBAUER, P. Galloping elephants: Developing elements of a theory of effective government organizations. Journal of public administration research and theory, v. 9, n. 1, p. 1-32, 1999. DOI: https://doi.org/10.1093/oxfordjournals.jpart.a024401.

VANDENABEELE, W. Toward a public administration theory of public service motivation: An institutional approach. Public management review, v. 9, n. 4, p. 545-556, 2007. DOI: https://doi.org/10.1080/14719030701726697.

VANDENABEELE, W.; RITZ, A.; NEUMANN, O. Public service motivation: state of the art and conceptual cleanup. In: ONGARO, E; THIEL, V. S. (Org.). The Palgrave Handbook of Public Administration and Management in Europe. Palgrave Macmillan, London, 2018. p. 261-278. DOI: http://dx.doi.org/10.1057/978-1-137-55269-3.

WRIGHT, B. E.; CHRISTENSEN, R. K.; PANDEY, S. K. Measuring public service motivation: Exploring the equivalence of existing global measures. International Public Management Journal, v. 16, n. 2, p. 197-223, 2013. DOI: https://doi.org/10.1080/10967494.2013.817242. 